\title{
Bilateral Versus Unilateral Upper Extremity Training on Upper Limb Motor Activity in Hemiplegia
}

\author{
Nafeez Syed ${ }^{1^{*}}$, Abhisek Biswas ${ }^{2}$, Nazia Hanifa ${ }^{3}$, Parameswaran RV ${ }^{4}$ and Padma Sundaram ${ }^{5}$ \\ ${ }^{1}$ Manipal College of Allied Health Sciences, Manipal Hospital, \# 98, Rustumbagh, H A L Airport Road, Bangalore - 560 017 , Karnataka, India \\ ${ }^{2}$ Neurorehabilitation Unit, Manipal Hospital, \# 98, Rustumbagh, H A L Airport Road, Bangalore - 560 017, Karnataka, India \\ ${ }^{3}$ Consultant Microbiologist, Infosys Tech Pvt. Ltd, Bangalore \\ ${ }^{4}$ Department of Nuclear Medicine and PET- CT, Manipal Hospital, \# 98, Rustumbagh, H A L Airport Road, Bangalore - 560 017, Karnataka, India \\ ${ }^{5}$ Department of Pulmonology, Manipal Hospital, \# 98, Rustumbagh, H A L Airport Road, Bangalore - 560 017, Karnataka, India
}

*Corresponding author: Nafeez Syed, Assistant Professor, Manipal College of Allied Health Sciences, Manipal Hospital, \# 98, Rustumbagh, H A L Airport Road, Bangalore - 560 017, Karnataka, India, E-mail: syed_nafeez@yaho.com

Rec date: Mar 09, 2014; Acc date: Mar 19, 2015; Pub date: March 25, 2015

Copyright: ( 2015 Syed $\mathrm{N}$ et al. This is an open-access article distributed under the terms of the Creative Commons Attribution License, which permits unrestricted use, distribution, and reproduction in any medium, provided the original author and source are credited.

\begin{abstract}
Background: Upper extremity paresis post stroke is an important contributor to disability and task oriented rehabilitation aims at compensating loss of function in the affected upper extremity. Bilateral arm training focuses on coupling both the extremities during treatment to gain symmetrical and synchronous movement in both the limbs.

Objective: To analyze the efficacy of bilateral arm training over unilateral training in improving upper limb functional tasks of subjects with hemiplegia.

Methods: 30 hemiplegic subjects were randomly assigned into experimental and control groups where the former performed three sets of exercises using both the upper extremities while those in the latter group performed same exercises using only the affected extremity. Motor Activity Log (MAL) was used to quantify the treatment outcome. Results: Pre-post comparison within groups showed significant improvement in AOU (amount of usage) and QOM (quality of movement ) components of $\operatorname{MAL}(p<0.001)$ in both experimental and control groups, whereas only $A O U$ showed significant difference between the groups $(p<0.05)$. Conclusion: Bilateral arm training improved functional tasks better than unilateral arm training in subjects with hemiplegia.
\end{abstract}

Keywords: Stroke; Bilateral arm training; Unilateral arm training; Motor activity log

\section{Introduction}

Hemiplegia in stroke is attributable to the involvement of corticospinal system on the side opposite to paralysis [1] leading to motor deficits. Decreased paretic arm function due to inadequate muscle recruitment, flaccidity in muscle, abnormal muscle tone, and uncoordinated response are important contributors to post stroke disability [2-4]. Upper limb recovery in most of the stroke subjects is dramatic within the first three months post stroke but plateaus by six months causing most of the stroke survivors remain unable to functionally use their affected hand [5]. 30-66\% of all individuals with hemiparesis have poor arm function 6 months post-stroke and a phenomenon of learned non-use sets in 6 resulting in secondary complications like muscle atrophy, pain, joint sub-luxation and impaired circulation to the affected limb [7]. A vicious cycle and reluctance to use the affected arm impedes the motor and functional recovery. Thus functional recovery of the paretic upper extremity has been a long standing struggle for patients and therapists alike which represent the dominant function limitation in as much as $80 \%$ of patients with acute stroke $[8,9]$.

Intervention using traditional therapeutic approaches results in continued impairment in $50-95 \%$ of patients [10-12] leading to the evolution of general traditional techniques to specific techniques like constraint induced therapy [13], task specific treatment training [14], mental imagery [15] and inter-limb coupling 16 on the paretic limb. It has been established in stroke that even if one upper limb is activated with moderate force, it can produce motor overflow to the other limb such that both arms are engaged in the same or opposite muscle contractions, although at different levels of force $[17,18]$. Furthermore studies suggest that learning a novel motor skill with one arm will result in a subsequent bilateral transfer of skill to the other arm [19] indicating a strong neurophysiological linkage in the central nervous system that explains how bilateral movement benefits motor learning.

Recent evidence supports the efficacy of active rehabilitation reflecting that patients can benefit most when they are actively involved in their treatment (eg; selection of treatment tasks and setting goals). Bilateral Arm Training emphasizes both upper extremities, which simultaneously practice functional tasks possibly due to inter hemispheric coupling and neural cross-talk. In a recent meta-analysis of bilateral movement training, outcomes were positive overall during sub-acute and chronic phases of recovery [20] which might have been due to positive neural effects for both hemispheres, whereas unilateral training might result in reorganization of the ipsilesional hemisphere.

The recovery of the movement patterns and its applicability in functional tasks are quantified using various outcomes. Motor Activity $\log (\mathrm{MAL})$ is one of those reliable and valid tools [21,22] which could be used exclusively to measure real world, upper extremity 
rehabilitation out come and functional status in chronic stroke patients with mild to moderate hemiparesis [23]. This has been used to assess the amount of use (AOU) and quality of movement (QOM) of the affected upper extremity in 30 daily activities using a 6-point scale. Studies in the past did not note improvements in all patients and bilateral training has not been shown to be better overall the other training approaches $[24,25]$. Hence, there is clearly a need to examine cortical plasticity associated with bilateral therapy in a larger group of sub-acute and chronic stroke patients and to determine the type of patient, in terms of side and site of lesion, who might benefit most from bilateral training. The dearth of large randomized controlled trials [26] with little evidence on long-term training effects for bilateral arm training warrants a study to test the efficacy of bilateral arm training program in improving the functional ability of the paretic upper limb in stroke.

\section{Methods}

In an experimental pre-post design, 30 sub-acute and chronic stroke subjects were recruited from the stroke unit of St Martha's hospital, Bangalore, and enrolled into the study. Subjects were screened for eligibility criteria and a written informed consent was taken before randomization of subjects into experimental group [bilateral extremity training; $\mathrm{n}=15$ ) and control group [unilateral extremity training; $n=15$ ]. Block randomization and concealed allocation using five blocks of six each was used to randomize the subjects into the two groups. Both men and women aged between 45-75 years, diagnosed with Middle Cerebral Artery (MCA) infarct leading to stroke within previous 6 months to 3 years (sub-acute and chronic) were enrolled. Subjects who had 200 and 100 of wrist and finger extension respectively in the affected upper extremity and a score of $\geq 2$ in upper arm functions section but $<2$ in advanced hand activities of Motor Assessment Scale (MAS) were considered. Subjects with communication and perceptual deficits, cognitive deficits (Modified Mini Mental State <20), musculoskeletal problems involving bilateral upper extremities, hearing and visual impairments and past history of neuro-muscular deficits involving either of the upper extremities were excluded.

\section{Intervention}

Subjects in experimental group were made to sit in a chair comfortably and perform three specific tasks using both arms simultaneously. Tasks administered were involving block placement, cup inversion and simulated drinking performed for 15 minutes each session for 5 sessions in a week for 3 weeks. In block placement, subject lifted a wooden block $(7 \times 5 \times 5 \mathrm{~cm})$ from the table and placed it on a target located on a $10 \mathrm{~cm}$ high box and were instructed to lift and place the block in one movement whilst trying to be as accurate as possible. During cup Inversion, subjects grasped the sides of an upside down plastic cup from the table and placed it right -side up on a target located on a $10 \mathrm{~cm}$ location whereas simulated drinking demanded subjects to pick a plastic cup within arm reach on the table and raise it to the mouth mimicking to drink. Subjects in the control group received similar tasks for 5 sessions a week for 3 weeks only for the affected extremity. AOU (Amount of use) and QOM (Quality of Movement) subscales of MAL (Motor Activity Log) were rated for affected upper extremity before and after intervention.

\section{Data Analysis}

Data were tested for normality using Kolmogorov-Smirnov test. A paired ' $t$ ' test was used to analyze the pre-post differences within the groups and the between group differences were analyzed using an Independent' $t$ ' test.

\section{Results}

Thirty subjects with a mean (SD) age of $59.6 \pm 4.5$ years and 61.7 \pm 3.7 years were enrolled into the experimental and control groups respectively. Amongst the subjects in the experimental group, 9 (60\%) were men and $6(40 \%)$ were women, whereas those in control group were $11(73.3 \%)$ men and $4(26.6 \%)$ women respectively. Data were found to follow normal distribution with a $p>0.05$ for age, AOU and QOM subscales, indicating no significant difference between the groups at baseline. At baseline, subjects in the experimental group had a mean (SD) AOU \& QOM values of $1.4(0.8)$ and $2.2(0.8)$ whereas those in the control group the values were $1.5(0.3)$ and $2.0(0.6)$ respectively. Subjects in both groups had co-morbidities like diabetes mellitus, hypertension, history of smoking and alcoholism and their numbers are as shown in Table 1. BMI of interventional and control groups were $26.8 \pm 4.4 \mathrm{~kg} / \mathrm{m} 2$ and $26.2 \pm 3.9 \mathrm{~kg} / \mathrm{m}^{2}$ respectively.

\begin{tabular}{|c|c|c|c|c|}
\hline Description & Experimental group & Control group & Kolmogorov-Smirnov Z & $p$ value \\
\hline No of Subjects (n) & 15 & 15 & \multicolumn{2}{|l|}{ - } \\
\hline Male: Female (n) & 9:6 & $11: 4$ & \multicolumn{2}{|l|}{ - } \\
\hline Age (Mean SD) & 59.64 .5 & 61.73 .7 & 0.39 & $0.99^{*}$ \\
\hline Pre intervention $\mathrm{AOU}($ Mean SD) & 1.40 .8 & 1.50 .3 & 0.55 & $0.91^{*}$ \\
\hline Pre intervention QOM & 2.20 .8 & 2.00 .6 & 0.88 & $0.41^{*}$ \\
\hline \multicolumn{5}{|l|}{ Comorbidities } \\
\hline Diabetes (n) & 12 & 13 & & \\
\hline Hypertension (n) & 9 & 10 & & \\
\hline Smoking (n) & 8 & 9 & & \\
\hline
\end{tabular}


Citation: Syed N, Biswas A, Hanifa N, Parameswaran RV, Sundaram P (2015) Bilateral Versus Unilateral Upper Extremity Training on Upper Limb Motor Activity in Hemiplegia. Int J Neurorehabilitation 2: 1000145. doi:10.4172/2376-0281.1000145

Page 3 of 6

\begin{tabular}{|l|l|l|l|}
\hline Alcoholism (n) & 6 & 5 & \multirow{2}{*}{} \\
\cline { 1 - 3 } BMI (Mean \pm SD) & $26.8 \pm 4.4 \mathrm{~kg} / \mathrm{m} 2$ & $26.2 \pm 3.9 \mathrm{~kg} / \mathrm{m} 2$ & \\
\hline
\end{tabular}

Table 1: Demographic details of the subjects

Post intervention, both groups showed significant improvements in AOU and QOM scores of MAL $(\mathrm{p}<0.001)$. AOU scores in the experimental group improved from $1.90 \pm 0.85$ to $2.61 \pm 0.80$ and those in the control group improved from $1.00 \pm 0.65$ to $1.39 \pm 0.60$.
Similarly, QOM scores improved from $2.64 \pm 0.85$ to $3.26 \pm 0.61$ and $1.84 \pm 0.77$ to $2.24 \pm 0.56$ in experimental and control groups respectively (Table 2).

\begin{tabular}{|l|l|l|l|l|l|l|l|l|}
\hline \multicolumn{9}{|c|}{ Within group Analysis } \\
\hline Group & Bilateral Training/Experimental & \multicolumn{3}{l|}{ Unilateral Training/Control } \\
\hline Outcome & $\begin{array}{l}\text { Pre test } \\
\text { Mean } \pm \text { SD }\end{array}$ & $\begin{array}{l}\text { Post test } \\
\text { Mean } \pm \mathrm{SD}\end{array}$ & $\mathrm{t}$ & $\mathrm{p}$ value & $\begin{array}{l}\text { Pre test } \\
\text { Mean } \pm \mathrm{SD}\end{array}$ & $\begin{array}{l}\text { Post test } \\
\text { Mean } \pm \mathrm{SD}\end{array}$ & $\mathrm{t}$ & $\mathrm{p}$ value \\
\hline AOU & $1.90 \pm 0.85$ & $2.61 \pm 0.80$ & -7.83 & $0.001^{*}$ & $1.00 \pm 0.65$ & $1.39 \pm 0.60$ & -7.42 & $0.001^{*}$ \\
\hline QOM & $2.64 \pm 0.85$ & $3.26 \pm 0.61$ & -5.55 & $0.001^{*}$ & $1.84 \pm 0.77$ & $2.24 \pm 0.56$ & -3.82 & $0.002^{*}$ \\
\hline
\end{tabular}

Table 2: Within group comparison of AOU and QOM scores in experimental \& control groups. ${ }^{*} \mathrm{p}<0.05$

Between groups comparison showed a significant difference $(\mathrm{p}<$ $0.05)$ in AOU subscale whereas not so significant difference was noted between the QOM sub-scale of MAL (Table 3).

\begin{tabular}{|l|l|l|l|l|}
\hline \multicolumn{5}{|c|}{ Between group Analysis } \\
\hline $\begin{array}{l}\text { Group } \\
\text { Outcome }\end{array}$ & $\begin{array}{l}\text { Experimental/ Bilateral Training Post - Pre } \\
(\text { Mean } \pm \text { SD) }\end{array}$ & $\begin{array}{l}\text { Control/ Unilateral Training Post - Pre (Mean } \\
\pm \text { SD) }\end{array}$ & $T$ & $p$ value \\
\hline AOU & $0.70 \pm 0.34$ & $0.39 \pm 0.20$ & 2.99 & $0.006^{*}$ \\
\hline QOM & $0.62 \pm 0.40$ & $0.40 \pm 0.40$ & 1.47 & 0.152 \\
\hline
\end{tabular}

Table 3: Between groups comparison of AOU and QOM scores of experimental and control groups, ${ }^{*} \mathrm{p}<0.05$

\section{Discussion}

This study compared the effect of bilateral extremity training over unilateral extremity training in improving upper extremity functional tasks of subjects with sub-acute and chronic stroke. Results showed significant improvements in Motor Activity Log scores (AOU and $\mathrm{QOM}$ ) of both the groups; however, between the groups, there was significant difference only in the amount of usage (AOU) of upper extremity for functional tasks. The results of this study suggest that training involving the practice of simultaneous actions bilaterally may be effective in promoting recovery of upper limb motor function in sub-acute and chronic stroke patients.

Sub-acute and chronic stroke subjects were enrolled for training in this study as only few reports are available on the effect of training regimens focusing on bilateral use of upper limbs in both the postacute and chronic phases $[27,28]$. Coupling of homologous muscles being the preferred control mode of the motor system in healthy adults, results of this study recommend that this property can also be explored to promote functional recovery of a paretic limb in sub-acute and chronic stroke patients.
Activation of both hemispheres is common during complex tasks, as well as tasks performed by the non-dominant hand in healthy subjects [29] and involvement of contralesional hemisphere was reported to be more in the control of movements [30]. Since the tasks used in this study involved arm movements with distal upper extremity activities (complex tasks), similar pattern of activation in both motor cortex and supplemental motor areas [31,32] would have resulted improvement in both types of training. Nevertheless, our observations contradict with those of Lewis and Byblow [33] who suggest that bilateral extremity training may not be beneficial if the task is too complex for the patient. Despite not known if this cortical activation facilitates or inhibits, we incline to believe that the activation is facilitory in nature considering the improvements in AOU and QOM of subjects in both the groups. Lack of difference in the improvements between the groups concurs with the opinions of Lewis GN, Byblow WD, Mesier S et al. and Tjis E et al. [33-35].

It has been hypothesized that practicing bilateral symmetrical movements may facilitate motor output from the ipsilesional hemisphere by normalizing the transcollosal inhibition influences [36]. Repetitive practice of simultaneous bilateral movements and permanent synaptic enrichment of reorganized neural pathways may 
occur through a neuronal plastic process [37] which might have led to a significant improvement in unilateral extremity training group. Also, task specific nature of exercises and simulation training could have had an impact on the improvements which are consistent with those reported in previous study [38]. Our findings showed that bilateral extremity training is efficacious in improving the amount of arm usage though the quality of movement did not significantly improve. Normalization of transcallosal inhibitory mechanisms between the hemispheres [39] and neuroplasticity changes [40] could be the possible neural mechanisms underlying post-stroke functional improvements following bilateral training. Our findings concur to those of Cunningham et al. [41] who reported inter-limb coupling dynamics with bilateral extremity training in turn leading to a better amount of use (AOU) of affected extremity. Results published by Luft $\mathrm{AR}$ et al. [42] were also found to be congruent where implication of contralesional hemisphere was found to improve movement of the affected elbow with bilateral extremity training with rhythmic auditory cueing.

The improvement noted in both bilateral and unilateral extremity training groups could also be attributed to the changes in cortical sensorimotor maps and improvements in motor function which have been reported to occur as a result of induced interventions post-stroke $[43,44]$. Bilateral arm activities that have been used in this study such as block placement, cup inversion and simulated drinking though not identical but are similar to the tasks used by Weiss P H et al. [45] Despite bilateral tasks may have dissimilar unilateral demands, a strong coupling exists between the arms when they act together which is essentially unique and different to the unilateral skills which compose the bilateral task. This could have resulted in the better amount of use (AOU) of the affected extremity in the bilateral extremity training group compared to those in unilateral group. However, we differ from the findings of few authors who reported no facilitation effects to the affected limb (arm or leg) during inter-limb coordination conditions which could be due to negative effects on the non-paretic arm during bilateral movements [46].

There has been a mixed opinion on the unilateral training paradigms as most believed in reorganization in the ipsilesional cortices [47-52] whereas few others believed in persistent inhibition with no change in facilitation of the ipsilateral hemisphere [53]. Authors of this study are in agreement with those who reported persistent inhibition during unilateral training. This could be the reason why the unilateral extremity training group did not improve in the amount of usage of affected extremity in comparison to those in the bilateral training group. Findings in our study add to the evidence on role of ipsilateral pathways in post-stroke upper limb recovery which has not been clarified till date. Though, proponents of symmetry constraint [54] in post stroke bilateral training believe in greater use of the ipsilateral pathways [55], some evidence indicate that the recruitment of the ipsilateral pathways post stroke is associated with a less than optimal motor outcome [56].

When a neurologically intact individual performs a unilateral movement, inter-hemispheric inhibition (Transcollosal inhibition) of the non-target hand occurs to enhance independent bimanual control of each limb [57].Whereas, during bilateral movement, independent control of each limb is not essential, rendering trans-callosal inhibition unnecessary [58]. This dis-inhibition may allow the ipsilateral cortex and descending pathways to contribute more extensively in the improved movement and performance of the hemiplegic limb $[33,59,60]$. This could have played a significant role in improving the amount of usage of upper extremity function following bilateral arm training. Quality of Movement between the two training groups did not differ significantly which could have been due to the diverse extent of damage to the corticospinal pathways in the study subjects. Similar findings were reported by Ward NS et al. [61] Liepert et al. [62] and Hamzei et al. [63] who noted the impact of extent and location of lesion on motor cortex excitability respectively.

Though the authors in this study noted both bilateral and unilateral trainings to be efficacious for moderately impaired sub-acute and chronic stroke survivors, bilateral training weighed more advantageous for proximal arm function. This was similar to that reported in one of the studies in the past [64]. Through this study, authors conclude that bilateral training is better than unilateral training in chronic stroke survivors. Till date there is insufficient good quality evidence on the relative effect of simultaneous bilateral training compared to placebo, no intervention or usual care. Future studies comparing the effects of unilateral and bilateral arm training in isolation with a control group and their combined effect with control and placebo groups are recommended.

\section{Acknowledgement}

Authors acknowledge all the participants for their support in this trial and fellow colleagues of department of Physiotherapy, Manipal Hospital St Marthas Hospital for their constructive criticism.

\section{References}

1. Raymond D (1997) Adams: Principles of Neurology, McGraw-Hill, US, Pp: 60.

2. Church Catherine, Price Christopher (2006) Randomized Controlled Trial to Evaluate the effect of Surface Neuromuscular Electrical Stimulation to the Shoulder After Acute Stroke. Stroke 37:2995-3001.

3. Duncan PW (1997) Synthesis of intervention trials to improve motor recovery following stroke. Top Stroke Rehabil. 3:1-20.

4. Sunderland A, Tinson D, Bradley L, Hewer RL (1989) Arm function after stroke. An evaluation of grip strength as a measure of recovery and a prognostic indicator. J Neurol Neurosurg Psychiatry 52: 1267-1272.

5. Parker VM, Wade DT, Langton Hewer R (1986) Loss of arm function after stroke: measurement, frequency, and recovery. Int Rehabil Med 8: 69-73.

6. Taub E, Cargo JE, Uswatte G (1998) Constraint induced movement therapy: a new approach to treatment in physical rehabilitation. Rehabil.Psychology. 43: 52-170.

7. Feys HM, De Weerdt WJ, Selz BE, Cox Steck GA, Spichiger R, et al. (1998) Effect of a therapeutic intervention for the hemiplegic upper limb in the acute phase after stroke: a single-blind, randomized, controlled multicenter trial. Stroke 29: 785-792.

8. Jorgensen HS, Nakayama H, Raaschou HO, Vive-Larsen J, Stoier M, et al., (1995) Outcome and time course of recovery in stroke. Part I: Outcome. The Copenhagen Stroke Study. Arch Phys Med Rehabil 76:399-405.

9. Nakayama H, Jorgensen HS, Raaschou HO, Olsen TS (1994) Recovery of Upper Extremity Function in Stroke Patients: The Copenhagen Study. Archives of Physical Medicine and Rehabilitation 75:852-857.

10. Gowland C, deBruin H, Basmajian JV, Plews N, Burcea I (1992) Agonist and antagonist activity during voluntary upper-limb movement in patients with stroke. Phys Ther 72: 624-633.

11. Gresham GE, Fitzpatrick TE, Wolf PA, McNamara PM, Kannel WB, et al. (1975) Residual disability in survivors of stroke-the Framingham study. N Engl J Med 293: 954-956.

12. Mayo NE, Wood-Dauphinee S, Ahmed S, Gordon C, Higgins J, et al. (1999) Disablement following stroke. Disabil Rehabil 21: 258-268. 
13. Uswatte G, Taub E, Morris D, Barman J, Crago J (2006) Contribution of the shaping and restraint components of Constraint-Induced Movement therapy to treatment outcome. NeuroRehabilitation 21: 147-156.

14. McDonnell MN, Hillier SL (2007) Influence of combined afferent stimulation and task-specific training following stroke: a pilot randomized controlled trial. Neurorehabil.Neural Repair. 21:435-443.

15. Johnson SH, Sprehn G, Saykin AJ (2002) Intact motor imagery in chronic upper limb hemiplegics: evidence for activity-independent action representations. J Cogn Neurosci 14: 841-852.

16. Harris-Love ML, McCombe Waller S, Whitall J (2005) Exploiting interlimb coupling to improve paretic arm reaching performance in people with chronic stroke. Arch Phys Med Rehabil 86: 2131-2137.

17. Carey JR, Allison JD, Mundale MO (1983) Electromyographic study of muscular overflow during precision handgrip. Phys Ther 63: 505-511.

18. Geffen GM, Jones DL, Geffen LB (1994) Interhemispheric control of manual motor activity. Behav Brain Res 64: 131-140.

19. Lazarus JC, Whitall J, Franks CA (1995) Age difference in isometric force regulation. J Exp Child Psychol. 60: 245-260.

20. Stewart KC, Cauraugh JH, Summers JJ (2006) Bilateral movement training and stroke rehabilitation: a systematic review and meta-analysis. J Neurol Sci 244: 89-95.

21. Uswatte G, Taub E, Morris D, Light K, Thompson PA (2006) The Motor Activity Log-28: assessing daily use of the hemiparetic arm after stroke. Neurology 67: 1189-1194.

22. van der Lee JH, Beckerman H, Knol DL, de Vet HC, Bouter LM (2004) Clinimetric properties of the motor activity log for the assessment of arm use in hemiparetic patients. Stroke 35: 1410-1414.

23. Uswatte G, Taub E, Morris D, Vignolo M, McCulloch K (2005) Reliability and validity of the upper-extremity Motor Activity Log-14 for measuring real-world arm use. Stroke 36: 2493-2496.

24. Platz T, Bock S, Prass K (2001) Reduced skillfulness of arm motor behavior among motor stroke patients with good clinical recovery: does it indicate reduced automaticity? Can it be improved by unilateral or bilateral training? A kinematic motion analysis study.Neuropsychologia 39:687-698.

25. Whitall J, McCombe Waller S, Silver KH, Macko RF (2000) Repetitive bilateral arm training with rhythmic auditory cueing improves motor function in chronic hemiparetic stroke. Stroke 31: 2390-2395.

26. Van Peppen RP, Kwakkel G, Wood-Dauphinee S, Hendriks HJ, Van der Wees PJ, et al. (2004) The impact of physical therapy on functional outcomes after stroke: what's the evidence? Clin Rehabil 18: 833-862.

27. Mudie MH, Matyas TA (2000) Can simultaneous bilateral movement involve the undamaged hemisphere in reconstruction of neural networks damaged by stroke? Disabil Rehabil 22: 23-37.

28. Whitall J, McCombe Waller S, Silver KH, Macko RF (2000) Repetitive bilateral arm training with rhythmic auditory cueing improves motor function in chronic hemiparetic stroke. Stroke 31: 2390-2395.

29. Debaere F, Wenderoth N, Sunaert S, Van Hecke P, Swinnen SP (2004) Changes in brain activation during the acquisition of a new bimanual coodination task. Neuropsychologia 42: 855-867.

30. Schaechter JD, Perdue KL (2008) Enhanced cortical activation in the contralesional hemisphere of chronic stroke patients in response to motor skill challenge. Cereb Cortex 18: 638-647.

31. Donchin O, Gribova A, Steinberg O, Bergman H, Vaadia E (1998) Primary motor cortex is involved in bimanual coordination. Nature 395: 274-278.

32. Tanji J, Okano K, Sato KC (1988) Neuronal activity in cortical motor areas related to ipsilateral, contralateral, and bilateral digit movements of the monkey. J Neurophysiol 60: 325-343.

33. Lewis GN, Byblow WD (2004) Neurophysiological and behavioural adaptations to a bilateral training intervention in individuals following stroke. Clin Rehabil 18: 48-59.

34. Messier S, Bourbonnais D, Desrosiers J, Roy Y (2006) Kinematic analysis of upper limbs and trunk movement during bilateral movement after stroke. Arch Phys Med Rehabil 87: 1463-1470.
35. Tijs E, Matyas TA (2006) Bilateral training does not facilitate performance of copying tasks in poststroke hemiplegia. Neurorehabil Neural Repair 20: 473-483.

36. Cauraugh JH, Summers JJ (2005) Neural plasticity and bilateral movements: A rehabilitation approach for chronic stroke. Prog Neurobiol 75: 309-320.

37. Sakamoto T, Porter LL, Asanuma H (1987) Long-lasting potentiation of synaptic potentials in the motor cortex produced by stimulation of the sensory cortex in the cat: a basis of motor learning. Brain Res 413: 360-364.

38. McDonnell MN, Hillier SL (2007) Influence of combined afferent stimulation and task-specific training following stroke: a pilot randomized controlled trial. Neurorehabil.Neural Repair 21:435-443.

39. Stinear CM, Barber PA, Coxon JP, Fleming MK, Byblow WD (2008) Priming the motor system enhances the effects of upper limb therapy in chronic stroke. Brain 131: 1381-1390.

40. Cauraugh JH, Summers JJ (2005) Neural plasticity and bilateral movements: A rehabilitation approach for chronic stroke. Prog Neurobiol 75: 309-320.

41. Cunningham CL, Stoykov ME, Walter CB (2002) Bilateral facilitation of motor control in chronic hemiplegia. Acta Psychol (Amst) 110: 321-337.

42. Luft AR, McCombe-Waller S, Whitall J, Forrester LW, Macko R, Sorkin JD, et al. (2004) Repetitive bilateral arm training and motor cortex activation in chronic stroke: a randomized controlled trial. JAMA 292: 1853-1861.

43. Nelles G, Jentzen W, Jueptner M, Müller S, Diener HC (2001) Arm training induced brain plasticity in stroke studied with serial positron emission tomography. Neuroimage 13: 1146-1154.

44. Liepert J, Bauder H, Wolfgang HR, Miltner WH, Taub E, et al. (2000) Treatment-induced cortical reorganization after stroke in humans. Stroke 31: 1210-1216.

45. Weiss PH, Jeannerod M, Paulignan Y, Freund HJ (2000) Is the organisation of goal-directed action modality specific? A common temporal structure. Neuropsychologia 38: 1136-1147.

46. Garry MI, van Steenis RE, Summers JJ (2005) Interlimb coordination following stroke. Hum Mov Sci 24: 849-864.

47. Carey JR, Allison JD, Mundale MO (1983) Electromyographic study of muscular overflow during precision handgrip. Phys Ther 63: 505-511.

48. Jang SH, Han BS, Chang Y, Byun WM, Lee J, et al. (2002) Functional MRI evidence for motor cortex reorganization adjacent to a lesion in a primary motor cortex. Am J Phys Med Rehabil 81: 844-847.

49. Johansen-Berg H, Dawes H, Guy C, Smith SM, Wade DT, et al. (2002) Correlation between motor improvements and altered fMRI activity after rehabilitative therapy. Brain 125: 2731-2742.

50. Levy CE, Nichols DS, Schmalbrock PM, Keller P, Chakeres DW (2001) Functional MRI evidence of cortical reorganization in upper-limb stroke hemiplegia treated with constraint-induced movement therapy. Am J Phys Med Rehabil 80: 4-12.

51. Liepert J, Bauder H, Wolfgang HR, Miltner WH, Taub E, et al. (2000) Treatment-induced cortical reorganization after stroke in humans. Stroke 31: 1210-1216.

52. Schaechter JD, Kraft E, Hilliard TS, Dijkhuizen RM, Benner T, et al., (2002) Motor recovery and cortical reorganization after constraintinduced movement therapy in stroke patients: a preliminary study. Neurorehabil Neural Repair 16:326-338.

53. McCombe Waller S, Forrester LW, Villagra F, Whitall J (2008) Intracortical inhibition and facilitation with unilateral dominant, unilateral nondominant and bilateral movement tasks in left and right handed adults. J Neurol Sci 269:96-104.

54. Kelso JA1, Holt KG, Rubin P, Kugler PN (1981) Patterns of human interlimb coordination emerge from the properties of non-linear, limit cycle oscillatory processes: theory and data. J Mot Behav 13: 226-261.

55. Cauraugh JH, Summers JJ (2005) Neural plasticity and bilateral movements: A rehabilitation approach for chronic stroke. Prog Neurobiol 75: 309-320. 
Citation: Syed N, Biswas A, Hanifa N, Parameswaran RV, Sundaram P (2015) Bilateral Versus Unilateral Upper Extremity Training on Upper Limb Motor Activity in Hemiplegia. Int J Neurorehabilitation 2: 1000145. doi:10.4172/2376-0281.1000145

Page 6 of 6

56. Netz J, Lammers T, Hömberg V (1997) Reorganization of motor output in the non-affected hemisphere after stroke. Brain $120: 1579-1586$.

57. Gerloff C, Cohen LG, Floeter MK, Chen R, Corwell B, et al. (1998) Inhibitory influence of the ipsilateral motor cortex on responses to stimulation of the human cortex and pyramidal tract. J Physiol 510 : 249-259.

58. Mudie MH, Matyas TA (2000) Can simultaneous bilateral movement involve the undamaged hemisphere in reconstruction of neural networks damaged by stroke? Disabil Rehabil 22: 23-37.

59. Floel A, Nagorsen U, Werhahn KJ, Ravindran S, Birbaumer N, et al. (2004) Influence of somatosensory input on motor function in patients with chronic stroke. Ann Neurol 56: 206-212.

60. Takeuchi N, Chuma T, Matsuo Y, WatanabeI, Ikoma K (2005) Repetitive transcranial magnetic stimulation of contralesional primary motor cortex improves hand function after stroke. Stroke 36:1553-1566.
61. Ward NS, Newton JM, Swayne OB, Lee L, Thompson AJ, et al. (2006) Motor system activation after subcortical stroke depends on corticospinal system integrity. Brain 129: 809-819.

62. Liepert J, Restemeyer C, Kucinski T, Zittel S, Weiller C (2005) Motor strokes: the lesion location determines motor excitability changes. Stroke 36: 2648-2653.

63. Hamzei F, Liepert J, Dettmers C, Weiller C, Rijntjes M (2006) Two different reorganization patterns after rehabilitative therapy: an exploratory study with fMRI and TMS. Neuroimage 31: 710-720.

64. Stoykov ME, Lewis GN, Corcos DM (2009) Comparison of bilateral and unilateral training for upper extremity hemiparesis in stroke. Neurorehabil Neural Repair 23: 945-953. 